Supplement of Earth Surf. Dynam., 6, 487-503, 2018

https://doi.org/10.5194/esurf-6-487-2018-supplement

(C) Author(s) 2018. This work is distributed under

the Creative Commons Attribution 4.0 License.

(c) (1)

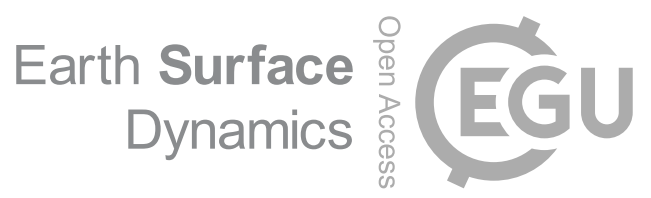

Supplement of

\title{
The influence of a vegetated bar on channel-bend flow dynamics
}

Sharon Bywater-Reyes et al.

Correspondence to: Sharon Bywater-Reyes (sharon.bywaterreyes@unco.edu)

The copyright of individual parts of the supplement might differ from the CC BY 4.0 License. 


\section{Supplement}

\section{Channel topography and model grid}

4 LiDAR was flown by Watershed Sciences, Inc. (now Quantum Spatial) for Missoula County on

5 October 30, 2012 with a Leica ALS60 with 3.83 ground points $/ \mathrm{m}^{2}$, providing 1-m resolution

6 topography with a RMSE of $0.03 \mathrm{~m}$. Inundated regions (reflected off water) were manually

7 removed. In-channel bathymetry was measured with RTK-GPS cross-section surveys (Trimble

8 R7 and 5800 with Trimble 5700 base station) augmented by Sonarmite echosounder

9 measurements in non-wadeable areas. Monuments used for the LiDAR survey were occupied

10 with the RTK GPS. Horizontal and vertical agreement of $<0.10 \mathrm{~m}$ was found. RTK topographic

11 points were interpolated in the downstream direction, as is appropriate in rivers. RTK point

12 density was $1.25 \mathrm{pts} \mathrm{m}^{-2}$. All topographic points were combined in iRIC, from which we made a

13 curvilinear orthogonal grid with a centerline following the general pattern of the channel over the

14 model domain with an average cell size of 2.5 by $2.5 \mathrm{~m}$ for calibration runs, and 5 by $5 \mathrm{~m}$ for the

15 remaining runs, with corresponding 841,851 and 210,926 nodes, respectively. We projected

16 Cartesian coordinate flow solution output to the nearest grid cell of a curvilinear grid (2 by $2 \mathrm{~m}$

17 average grid resolution) covering the channel bend of interest (Figure 3), and converted the

18 associated output to streamwise and stream-normal values with a rotation matrix. A piecewise

19 Cubic Hermite Interpolating Polynomial algorithm was applied to reduce artifacts from the

20 transformation. 
23 We surveyed water surface elevation (WSE) with RTK GPS in at least 30 WSE locations per

24 calibration over a $180 \mathrm{~m}$ reach length for each calibration flow (see main text). The calibrated

25 runs (Table 1; Fig. S1) had RMSE of $0.11-$ to $0.18 \mathrm{~m}$.
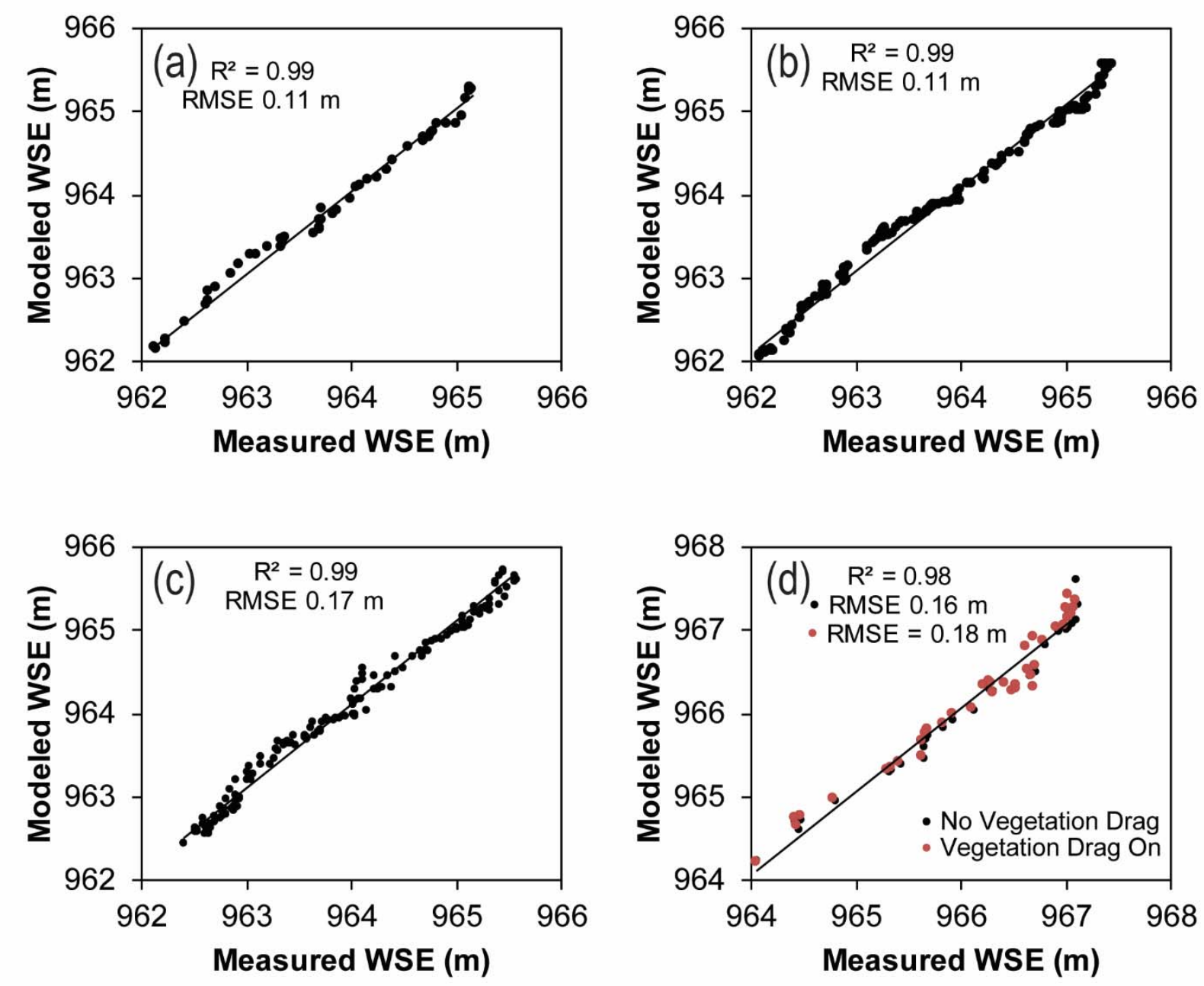

Figure S1. Water surface elevation (WSE) calibration for runs run 1 (a), 2 (b), 3 (c), 4 and 5 (d) (Table 1).

Velocity was measured during base flow in 2015 along cross sections in locations where

30 little geomorphic change was observed following topography collection (Fig. 1) using a

31 Teledyne RD Instruments (TRDI) four beam $1200 \mathrm{kHz}$ Rio Grande ADCP mounted to a $12-\mathrm{ft}$

32 cataraft equipped with rapid RTK GPS rowed manually. Data were collected using single ping 
33 ensembles with Bottom Mode 12 and Water Mode 7, similar to the methods described in Rennie

34 and Millar (2004), Rennie and Church (2010), and Venditti et al. (2015). Vertical velocity

35 resolution was $0.25 \mathrm{~m}$, with a minimum of four measurements. Velocities from the top $0.5 \mathrm{~m}$ and

36 bottom $6 \%$ of the depth were excluded. Velocities were corrected for boat speed with WinRiver

37 II software using bottom tracking. Bed conditions were immobile, so additional corrections were

38 not necessary.

39 Because velocity profiles were incomplete, data were exported in text format from

40 WinRiver II, and each ensemble post-processed for depth-averaged velocity $(\bar{U})$ in Matlab

41 R2012a by regressing velocity $(U)$ as a function of log of height above the bed $(z)$ to determine

42 shear velocity $\left(u^{*}\right)$ and roughness height $\left(z_{o}\right)$ (Bergeron and Abrahams, 1992). Since $U$ varies as

43 a function of $z$ :

44

$$
U=\frac{u_{*}}{\kappa} \ln \left(\frac{z}{z_{o}}\right)
$$

45 where $\kappa$ is the von Karman constant (0.41), the regression of $U$ as a function of z $(U z)$ yields:

$$
U=m_{U z} \ln (z)+c_{U z}
$$

47 where $m_{U Z}$ is slope and $c_{U z}$ the intercept. Shear velocity, $u_{* U Z}$, and roughness height, $z_{o_{U Z}}$, were 48 calculated from the regression coefficients:

$$
u_{* U z}=\kappa m_{U z}
$$

$$
z_{o_{U z}}=\exp \left(-c_{U z} / m_{U z}\right)
$$

51 Using the law of the wall and our calculated $u_{*_{U Z}}$ and $z_{o_{U Z}}$, we calculated $\bar{U}$ for each ensemble 52 assuming $z_{m}=0.37 \mathrm{H}$, where $\mathrm{H}$ is the total depth:

$$
\bar{U}=\frac{u_{*} U z}{\kappa} \ln \left(\frac{z_{m}}{z_{o_{U Z}}}\right)
$$


Individual ensembles are noisy (e.g., Rennie and Church, 2010) and we wished to

55 compare measured $\bar{U}$ to modeled $\bar{U}$. Thus we gridded measured velocities to match model

56 output, ensuring grid cells were concurrent and orthogonal, and calculated the root mean square

57 error (RMSE). We compared the RMSE of law-of-the-wall-derived $\bar{U}$ to a simple average

58 assuming missing values for the top $0.5 \mathrm{~m}$ in each ensemble were equal to the value of $U$

59 corresponding to the largest $z$. Law-of-the-wall-derived $\bar{U}$ had a lower RMSE, and was thus used

60 instead of the adjusted average (RMSE $0.24 \mathrm{~m} \mathrm{~s}^{-1}$ compared to $0.33 \mathrm{~m} \mathrm{~s}^{-1}$ ).

\section{Floodplain vegetation}

63 Individual floodplain trees were mapped (Fig. 1) from the airborne LiDAR, from which

64 vegetation density (\#stems $\mathrm{m}^{-2}$ ), height $(\mathrm{m})$ and diameter $(\mathrm{m})$ were extracted. Vegetation points

65 were isolated and ground vegetation removed with CloudCompare

66 (http://www.danielgm.net/cc/). The dataset was imported as a las dataset in ArcGIS 10.1 and a 1-

$67 \mathrm{~m}$ resolution raster of maximum height created. Crowns were mapped following a workflow

68 similar to Koch et al. (2006) in ArcGIS 10.1, whereby points were inverted and crowns

69 delineated in a manner similar to delineating drainage basins, and the maximum height for each

70 crown extracted as "basin" minima. Crown "basins" were converted to polygons. Method

71 performance was evaluated by comparing crown polygons to aerial imagery. Nearly every tree

72 large enough to be captured by the LiDAR was accurate ( $<5 \%$ false positive). Crown attributes

73 (centroid, area, and radius) were calculated using the field calculator. Height of each crown was

74 determined by intersecting centroids with the height raster. Diameter at breast height for each

75 tree was estimated by assuming a crown-diameter to stem-diameter relationship (Hemery et al., 
76 2005). Although this is a rough estimate, results were reasonable (mean diameter at breast height 77 of $0.20 \pm 0.14 \mathrm{~m}$ standard deviation).

78 Vegetation polygons were created by constructing a $15-\mathrm{m}$ bounding polygon. The

79 polygons were smoothed, gaps removed, and dissolved into a single polygon for each region.

80 Average polygon attributes were calculated (vegetation density (\#stems $\left.\mathrm{m}^{-2}\right)$, height $(\mathrm{m})$,

81 diameter (m), and $A_{C}$ (average flow depth multiplied by average diameter at breast height; $\mathrm{m}^{2}$

82 per plant).

83 


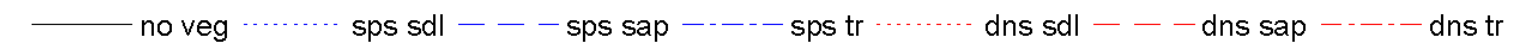
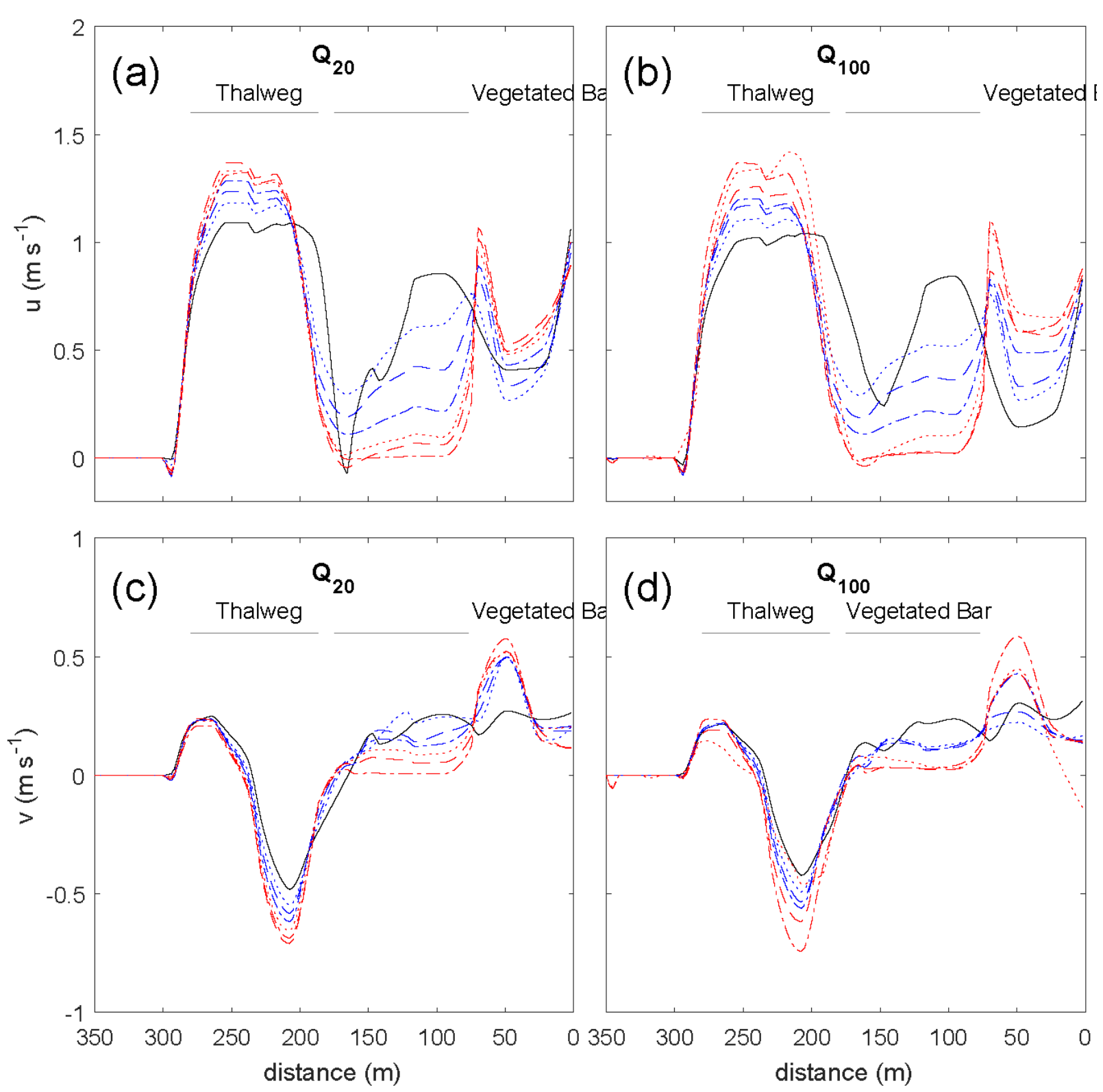

Figure S2. Effect of the vegetated bar $(j=33-75)$ on the streamwise $(u ; a, b)$ and stream-normal (v; c,d) velocity at the downstream cross section (XS1) for the $Q_{20}(a, c)$ and $Q_{100}(b, d)$ flows, with distance from river right end point (Figure 4). With increasing discharge, plant size (seedling to young trees) and density, $u$ is increased and $v$ decreased within the thalweg $(j=100)$. Both $u$ and $v$ (positive downstream and toward left bank, respectively) are decreased over the bar, and for the sparse young trees and all dense scenarios increased at the edge of the patch. The results for the $Q_{20}$ and $Q_{100}$, shown here, are similar to the $Q_{10}$ results (Figure 5). 

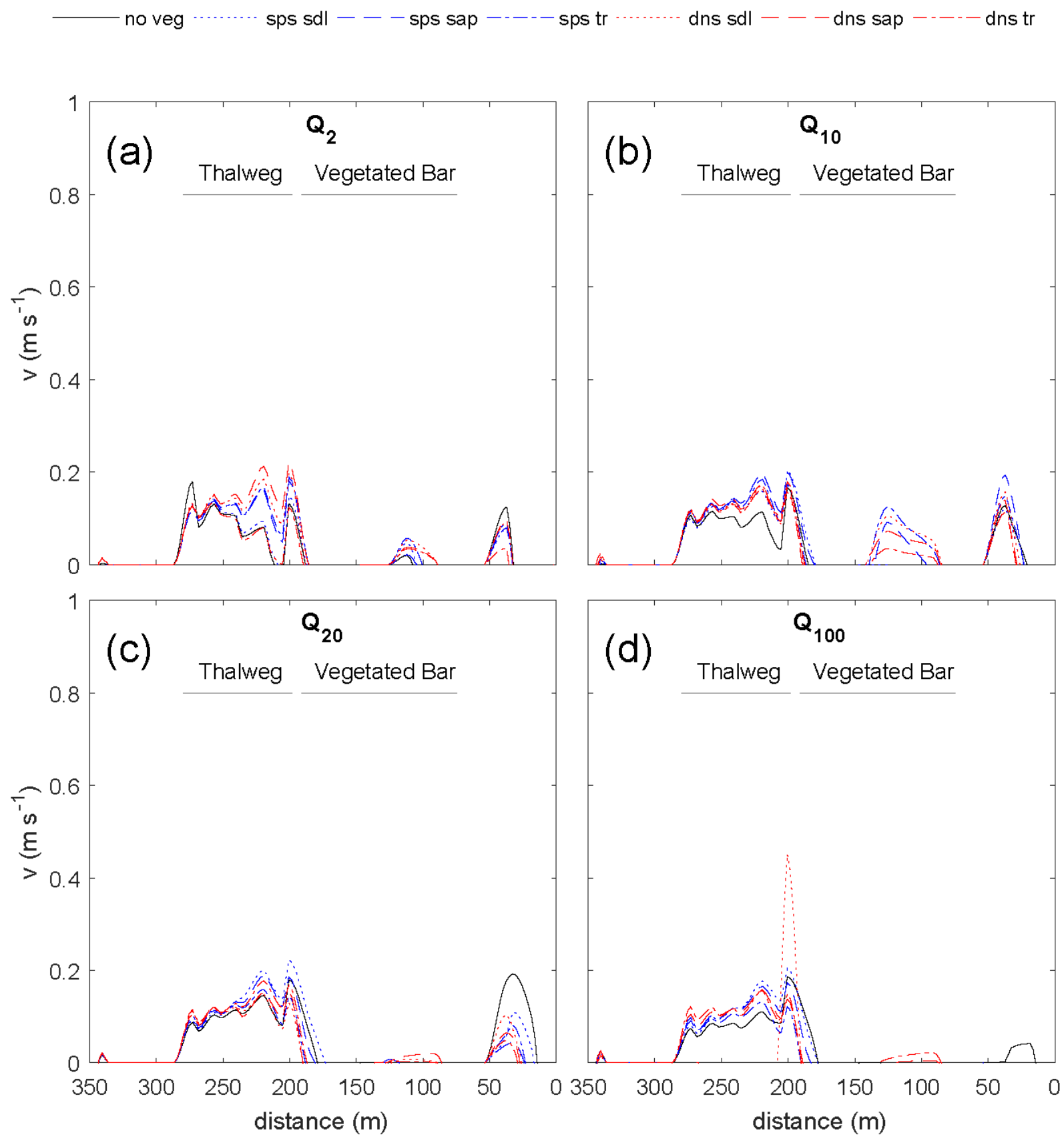

92

93

Figure S3. Effect of the vegetated bar $(j=32-82)$ on the stream-normal $(v)$ velocity at the midstream cross section (XS2) for the $Q_{2}(a), Q_{10}(b), Q_{20}(c)$, and $Q_{100}$ (d) flows, with distance from river right end point (Figure 4). In general, $v$ values are much smaller than $u$ values at XS2 (see Figure 6), and not substantially influenced by bar vegetation. 


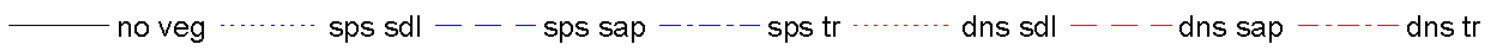
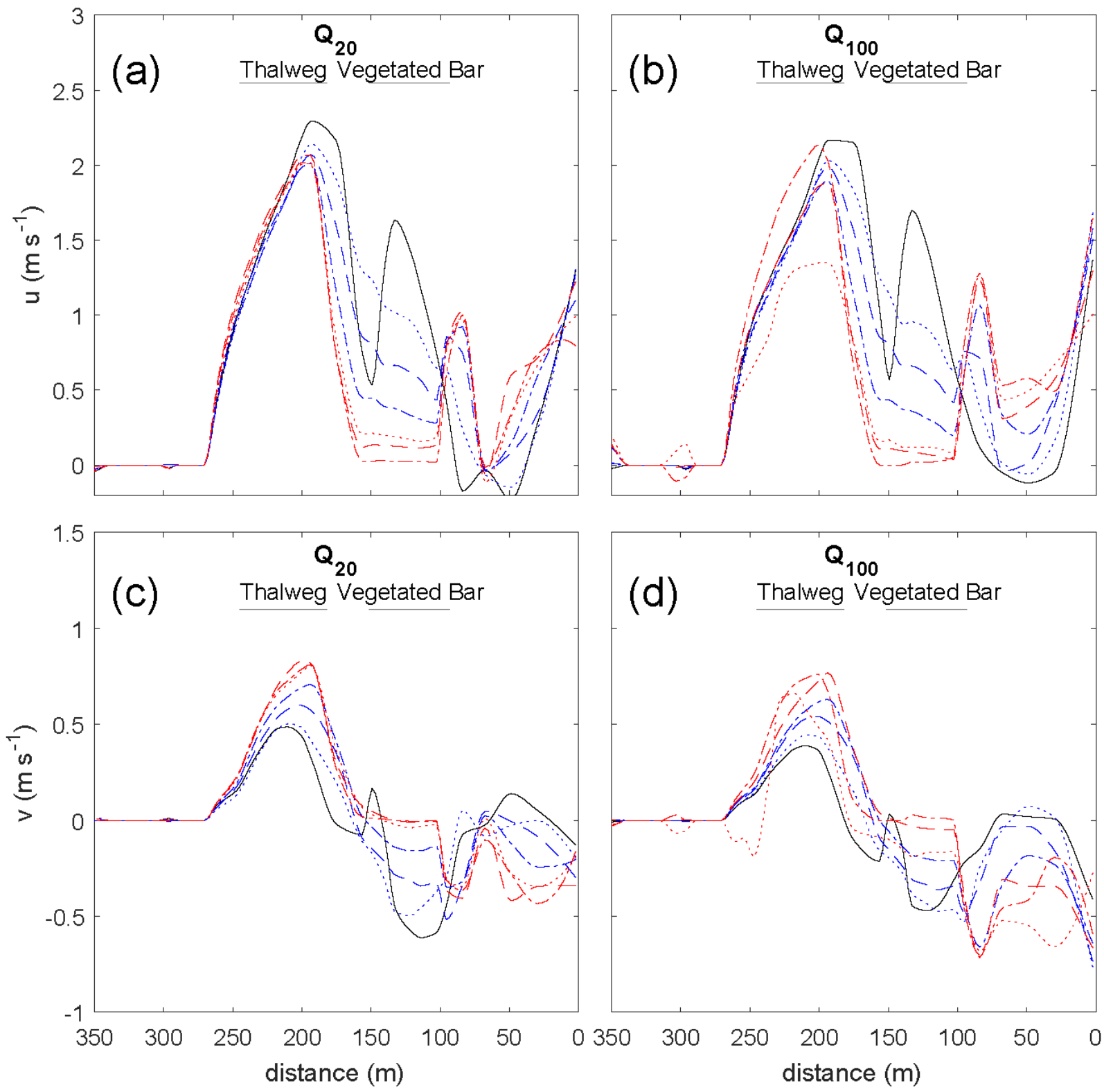

97

99

100

101

102

103

104

Figure S4. Effect of the vegetated bar $(j=50-65)$ on the streamwise $(u ; a, b)$ and stream-normal $(v$; c,d) velocity at the upstream cross section (XS1) for the $Q_{20}(a, c)$ and $Q_{100}(b, d)$ flows, with distance from river right end point (Figure 4). In the thalweg $(j=90)$ and at the head of the bar, $u$ is decreased with increasing seedling size and density. For $Q \geq Q_{10}, v$ became more negative adjacent to the vegetation patch. The results for the $Q_{20}$ and $Q_{100}$ are similar to that of the $Q_{10}$ flow (shown in Figure 7). 
$A_{c}=$ vegetation frontal area $\left(\mathrm{m}^{2}\right)$

108

$109 c_{U z}=$ intercept from regression of $U$ as a function of $z$

$110 m_{U z}=$ slope of regression of $U$ as a function $z$

$111 u_{*}=$ shear velocity

$112 u_{*_{U Z}}=$ shear velocity calculated from regression $U$ as a function of $z$

$113 \bar{U}=$ depth-averaged velocity $\left(\mathrm{m} \mathrm{s}^{-1}\right)$

$114 U=\operatorname{velocity}\left(\mathrm{m} \mathrm{s}^{-1}\right)$

$115 Z_{m}=$ height above bed corresponding to law-of-wall-predicted average velocity

$116 z_{o}=$ roughness height $(\mathrm{m})$

$117 z_{o_{U z}}=$ roughness height $(\mathrm{m})$ determined from regressing $U$ as a function of $z$

$118 \kappa=$ von Karman constant

Bergeron, N. and Abrahams, A.: Estimating shear velocity and roughness length from velocit profiles, Water Resour. Res., 28(8), 2155-2158, 1992.

124 Hemery, G. E., Savill, P. S. and Pryor, S. N.: Applications of the crown diameter-stem diameter relationship for different species of broadleaved trees, For. Ecol. Manage., 215(1-3), 285-294,

126 doi:10.1016/j.foreco.2005.05.016, 2005.

127 Koch, B., Heyder, U. and Weinacker, H.: Detection of Individual Tree Crowns in Airborne Lidar 128 Data, Photogramm. Eng. Remote Sens., 72(4), 357-363, doi:10.14358/PERS.72.4.357, 2006.

129 Rennie, C. D. and Church, M.: Mapping spatial distributions and uncertainty of water and 130 sediment flux in a large gravel bed river reach using an acoustic Doppler current profiler, J. 131 Geophys. Res., 115(F3), doi:10.1029/2009JF001556, 2010.

132 Rennie, C. D. and Millar, R. G.: Measurement of the spatial distribution of fluvial bedload 133 transport velocity in both sand and gravel, Earth Surf. Process. Landforms, 29(10), 1173-1193, 134 doi:10.1002/esp.1074, 2004.

135 Venditti, J. G., Domarad, N., Church, M. and Rennie, C. D.: The gravel-sand transition: 136 Sediment dynamics in a diffuse extension, J. Geophys. Res. Earth Surf., 120, 1-21, 
137 doi:10.1002/2014JF003328.Received, 2015.

138

139 